\title{
Automated Semantic Tagging of Textual Content
}

\author{
Jelena Jovanovic ${ }^{1}$, Ebrahim Bagheri², John Cuzzola², Dragan Gasevic ${ }^{3}$, Zoran Jeremic ${ }^{2}$, Reza \\ Bashash $^{4}$ \\ ${ }^{1}$ University of Belgrade, Belgrade, Serbia \\ jeljov@fon.bg.ac.rs \\ ${ }^{2}$ Ryerson University, Toronto, Canada \\ \{bagheri, jcuzzola, zoran.jeremic\}@ryerson.ca \\ ${ }^{3}$ Athabasca University, Athabasca, Canada \\ dgasevic@acm.org \\ ${ }^{4}$ SideBuy Technologies, Vancouver, Canada \\ bashash@gmail.com
}

\begin{abstract}
Motivated by a continually increasing demand for applications that depend on machine comprehension of text-based content, researchers, in both academia and industry, have developed innovative solutions for automated information extraction from text. In this article, we focus on a subset of such tools - i.e., semantic taggers - that not only extract and disambiguate entities mentioned in the text, but also identify topics that unambiguously describe the text's main themes. We offer insight into the process of semantic tagging, the capabilities and specificities of today's semantic taggers, and also indicate some of the criteria to be considered when choosing a tagger to use.
\end{abstract}

Keywords: I.2.7.h Text analysis $<$ I.2.7 Natural Language Processing $<$ I.2 Artificial Intelligence $<$ I Computing Methodologies; I.2.5.a Expert and knowledge-intensive system tools and techniques < I.2.5 Programming Languages and Software < I.2 Artificial Intelligence < I Computing Methodologies

\section{Introduction}

In the last few years, there has been a constant increase in the number and variety of online applications that rely on machine comprehension of human language to offer advanced functionalities such as semantic search, question answering, and recommendation. These functionalities are often enabled by information extraction services that couple Text Analysis and Machine Learning methods and techniques, with large, general-purpose knowledge bases such as Wikipedia.

Information Extraction - an active area of Text Analysis research - has seen a steady growth in the recent years [1]. The latest developments in data storage and processing, enabled by cloud infrastructure, have synergized many advanced Information Extraction methods and techniques, so that text can be processed and relevant information be extracted almost instantaneously. The significant increase in efficiency of automated text analysis has been coupled with an increase in the overall quality of extracted information. This made Information Extraction services highly appealing for a wide variety of real-world application areas such as:

- Knowledge management: information extraction from unstructured text can produce structured, unambiguous (meta-)data, and thus enable more effective and efficient search over and management of the organization's content repositories, as exemplified by the KnowMed (http://knowmed.com/) solution for healthcare and medical research. 
- Business analytics: tools such as RavenPack News Analytics

(http://www.ravenpack.com/services/rpna dj.htm) perform analysis of news articles in order to extract diverse kinds of entities and events that could be relevant for business decision making.

- Social media monitoring and reputation management: organizations and individuals can keep track of social media chatter and manage their reputation by leveraging Information Extraction techniques as showcased by Radian6 (http://radian6.com).

- Contextual advertising: solutions such as the one developed by ADmantX (http://www.admantx.com/) enable better positioning of advertisements on Web pages based on the semantics of the main content of the page, namely the entities mentioned in the text, the opinions and/or emotions expressed and the message the text aims to communicate.

In this article, we focus on one specific Information Extraction task, namely the extraction and disambiguation of entities and topics mentioned in or related to a given text. We refer to this task as semantic tagging, and the tools that perform this task as semantic taggers. After providing some insight into the task of semantic tagging and how it is typically performed, we offer a comparative overview of the state-of-the-art semantic taggers. However, this paper does not aim at providing an exhaustive and in-depth review of the semantic tagging techniques and algorithms. Instead, the objective is to inform IT practitioners about the new potentials offered through the employment of semantic taggers and to discuss practical issues related to the use of these tools such as the criteria to consider when choosing a tool.

\section{What are semantic tagging tools?}

Named Entity Recognition (NER) is a traditional Information Extraction task that consists of recognizing entities of a restricted set of types (e.g., Person, Organization, and Date) in a given text [2]. However, the richness of information that the state-of-the-art NER tools provide is rather limited in two significant ways. First, the set of supported entity types is restricted with the majority of tools only supporting up to a dozen types. Second, while NER tools can recognize that a piece of text represents a certain entity and its type, they cannot determine the 'identity' of the entity. For instance, in the sentence "Novak Djokovic is number one on the ATP list," a NER tool would identify Novak Djokovic as an entity of type Person. However, it would not be able to relate it to the corresponding real-world entity. The term "ATP" would impose an even greater challenge: whereas a NER tool might be able to recognize "ATP" as an entity of type Organization, it would have difficulties relating it with the Association of Tennis Professionals since this abbreviation can have many different meanings. The task of relating a piece of text with the actual intended real-world entity is called disambiguation or entity linking. It consists of relating an entity recognized in the text with an entry in a knowledge base e.g., Wikipedia - that uniquely identifies and provides further information about that entity.

Semantic tagging tools can be thought of as an advanced version of NER tools that do not suffer from the above stated deficiencies. Semantic tagging is a kind of formal (i.e., machine processable) information overlay that has explicitly defined semantics, typically expressed as a reference to an entity or resource defined in a knowledge base or ontology [3]. Semantic taggers overcome the limitations of NER tools; namely i) they are able to recognize all entity types that are defined in the underlying knowledge base or ontology, which are often in the order of thousands of types; and ii) their disambiguation processes are facilitated by the entities and resources explicitly defined in the underlying knowledge base or ontology. While the first generation of semantic tagging tools relied primarily on domain specific ontologies [3], today's state-of-the-art taggers are based on large, general-purpose, Web-based knowledge bases, primarily Wikipedia and its more structured and 
semantics-rich 'derivatives' such as DBpedia (http://dbpedia.org), YAGO (http://www.mpiinf.mpg.de/yago-naga/yago/), and Freebase (http://www.freebase.com/). The use of these large scale knowledge bases allows for overcoming the problem of ontology brittleness prevalent in the previous generation of semantic taggers [4] that caused a decline in their performance (especially recall) if the processed text spanned beyond the domain of the underlying lexicon.

\section{Kinds of semantic tagging tools}

Semantic tagging tools can be classified into manual, automated and semi-automated [3]. Manual tools require human participation throughout the tagging process. Automated taggers process the text in complete isolation and without any guidance from the user. Semi-automated taggers allow users to intervene in the tagging process by choosing the best option from the list of candidate tags, or by removing some of the proposed tags that they consider incorrect or irrelevant. The dependance on human active participation impacts the efficiency of manual and semi-automated tools and makes them less desirable for the kinds of application cases described earlier. Therefore, in this article, we focus on tools that allow for automated semantic tagging of textual content. For the sake of brevity, in the rest of the article we simply refer to this category of tools as taggers.

To further distinguish between different kinds of taggers, we use the types of problems and tasks they can deal with as the criteria for differentiation. Similar to [5], we identify the following types of tasks:

- Document topics - identifying topics (i.e., concepts from a knowledge base) that are relevant for the overall document.

- Document tagging - identifying entity mentions in the document and linking each mention to the appropriate concept(s) from the knowledge base.

- Suggestion of related topics - identifying topics that are not directly mentioned in the document, but are semantically related to the content of the document.

- Role assignment - identifying the role that a topic or a concept plays in the given context. For instance, in the sentence "Add the flavor of a banana to your recipe", "banana" would be disambiguated as a kind of fruit that has the "ingredient" role in the given context. In contrast, in "John threw a banana to the monkey", banana still refers to a fruit, but its role in this context would be "projectile".

In each of these types of tasks, each assigned topic, concept or role is often associated with a score indicating the likelihood that it is correct.

\section{Typical semantic tagging process}

The state-of-the-art taggers primarily rely on a combined use of text processing, large-scale knowledge bases, semantic similarity measures and machine learning techniques [5][6]. Even though each tool has its own unique approach to performing semantic tagging, some commonalities in the underlying methods of different tools can be observed. In particular, in our analysis of the state-of-theart taggers, we have identified three main phases in a typical tagging process: 1) detection of entity candidates, 2) disambiguation, and 3) result set pruning.

Detection ('spotting') of entity candidates. The objective of this phase is twofold: 1) to identify 'mentions' in the input text, which are the parts of text (single words or phrases) to be tagged; and 2) to identify a set of candidate entities from a knowledge base for each of the mentions. The detection (i.e., 'spotting') of mentions and candidate entities is typically done as a dictionary look-up task. Each tool functions over its own custom dictionary of terms that are matched against the input text. The 
dictionary is typically created through the extraction of entity labels and descriptions from a specific knowledge base. Some tools enrich each dictionary entry with statistical information such as the frequency of appearance in the knowledge base, link probability and co-occurrence rates.

Disambiguation. The purpose of this phase is to select, for each mention spotted in the text, the entity/entities that properly reflect(s) its/their semantics. The selection is made from among numerous candidate entities identified in the spotting phase. Numerous approaches have been proposed for accomplishing this task, which can be classified into the following generalized groups [7]:

- Popularity-based (mention-entity) prior consists of choosing the most prominent entity for a given piece of text, i.e., entity mention [8]. This approach is simple but could lead to erroneous results, which are often caused by the lack of proper attention to the entities' context and the main theme of the input text. For this reason, most taggers combine this approach with other approaches.

- Context-based approaches consider the context of the mention to be disambiguated, and compare it to the context of the candidate entities. The context of a mention is often modeled through bagof-words, based on which distance measures - such as cosine similarity measure [9] or Wikipedia links-based measure [8] - can be used to determine the similarity between any two given contexts.

- Collective disambiguation consists of jointly disambiguating multiple mentions in the input text. This can be viewed as an extension to the context-based approach in the sense that apart from considering context similarity scores of each mention-entity pair, the collective disambiguation approach also considers the coherence (i.e., semantic relatedness) of the target entities.

- Graph-based approach is a specific version of the collective disambiguation approach originally proposed by Hoffart et al. [7] and applied in their AIDA tool. In this approach, mentions and candidate entities are represented as vertices in a graph, while weighted edges between mentions and entities and also weighted edges among entities denote contextual similarity and coherence, respectively. Disambiguation is performed by identifying a dense sub-graph that contains exactly one mention-entity edge for each mention, indicating the most likely meaning for the given mention. Each of these approaches has its specific pros and cons and should be applied depending on the type of the input text. For instance, context-based approaches are suitable for sufficiently long and relatively clean input texts; however, they tend to produce weaker results for shorter texts such as tweets [5]. Hoffart et al. [7] suggested a procedure for selecting the best disambiguation approach depending on the characteristics of the input text.

Result set pruning. The objective of this phase is to remove tags that would be of no interest to the user, e.g., overly general tags or those that are just marginally related to the main subject of the text. Values of the filtering parameters can be either determined by the tool itself through experiments on different test datasets or set by the end users. However, not all tools perform result filtering as a separate task. For instance, AIDA and Lupedia [12] perform the final selection of the best mentionentity pairs in the disambiguation phase. In contrast, to meet the requirements of high generality and flexibility, DBpedia Spotlight postpones the final selection to the post-disambiguation phase, and allows its users to fine tune the selection through a number of configurable parameters [10].

\section{State-of-the-art semantic tagging tools}

No tagging tool is a priori better than any other, since its suitability depends on many factors such as who will be using it, what it will be used for, or which features are of the highest importance for the user [4]. Therefore, we have opted for a descriptive comparison of the current tagging tools. Our intention is to familiarize readers with inner workings of the available tools (Table 1) and to help them 
choose the tool(s) that fits their needs the best (Table 2). It should be noted that while some tools are open for public use, their implementation and algorithmic details are not necessarily available.

The first comparison framework (Table 1) is aimed at facilitating the comprehension of tools' similarities and differences in the main phases of the tagging process. Accordingly, it is focused on the 'white-box' features of 'open' tools, i.e., tools whose underlying approach to semantic tagging is made publicly available (e.g., in a scientific paper or a technical report). Among such tools, we selected those that can be either accessed directly as a Web service or downloaded and run locally. For each tool, we briefly describe the approach applied in each of the three main phases of the semantic tagging process, as well as the custom-made dictionary or dataset the tool uses in the entity-spotting and disambiguation phases.

Table 1. Comparison of 'white-box' features of open state-of-the-art semantic tagging tools. 


\begin{tabular}{|c|c|c|c|c|}
\hline & $\begin{array}{l}\text { Detection (spotting) of entity } \\
\text { candidates }\end{array}$ & Disambiguation* & Pruning the results set & $\begin{array}{l}\text { Source of entities used in entity } \\
\text { detection and disambiguation } \\
\text { phases }\end{array}$ \\
\hline TagMe [5] & $\begin{array}{l}\text { Dictionary-based: uses Ancor } \\
\text { Dictionary which is a custom- } \\
\text { made, indexed dictionary } \\
\text { comprising of anchor terms from } \\
\text { Wikipedia articles, titles of } \\
\text { Wikipedia pages and redirect } \\
\text { pages }\end{array}$ & $\begin{array}{l}\text { Combined use of popularity- } \\
\text { based prior and collective } \\
\text { disambiguation approaches }\end{array}$ & $\begin{array}{l}\text { Automated pruning of results: the } \\
\text { pruning is based on the average } \\
\text { value of two features: the link } \\
\text { probability of each mention, and } \\
\text { the coherence between its } \\
\text { candidate tag and the candidate } \\
\text { tags of the other mentions in the } \\
\text { input text (computed in the } \\
\text { disambiguation phase) }\end{array}$ & $\begin{array}{l}\text { Wikipedia-based Page Catalog } \\
\text { which is an indexed collection of } \\
\text { (titles of) all Wikipedia pages } \\
\text { except for disambiguation pages, } \\
\text { list pages, and redirect pages }\end{array}$ \\
\hline $\begin{array}{l}\text { DBpedia Spotlight } \\
{[10]}\end{array}$ & $\begin{array}{l}\text { Dictionary-based: uses a custom- } \\
\text { made dictionary (called Lexicon) } \\
\text { that associates DBpedia } \\
\text { resources with appropriate labels; } \\
\text { labels are created from titles of } \\
\text { Wikipedia articles, redirect and } \\
\text { disambiguation pages }\end{array}$ & Context-based approach & $\begin{array}{l}\text { User-defined pruning criteria: this } \\
\text { task relies on a number of } \\
\text { parameters tunable by the user; } \\
\text { e.g., the support parameter allows } \\
\text { for specifying the minimum } \\
\text { number of incoming links a } \\
\text { DBpedia resource has to have in } \\
\text { order to be used for tagging }\end{array}$ & $\begin{array}{l}\text { DBpedia Lexicalization dataset: } \\
\text { this dataset comprises the } \\
\text { Lexicon dictionary data encoded } \\
\text { using the Lexvo vocabulary } \\
\text { (http://www.lexvo.org/); } \\
\text { additionally, each association } \\
\text { between a resource and a label is } \\
\text { assigned a score (prior } \\
\text { probability) }\end{array}$ \\
\hline $\begin{array}{l}\text { Wikipedia Miner } \\
{[6]}\end{array}$ & $\begin{array}{l}\text { Pure text processing: detection of } \\
\text { all n-grams in the input text, and } \\
\text { keeping those whose link } \\
\text { probability exceeds a low } \\
\text { threshold set to discard only } \\
\text { nonsense phrases and stop } \\
\text { words. }\end{array}$ & $\begin{array}{l}\text { Combined use of popularity- } \\
\text { based prior and collective } \\
\text { disambiguation approaches }\end{array}$ & $\begin{array}{l}\text { Automated pruning of results: } \\
\text { done using a classifier that relies } \\
\text { on a number of features of } \\
\text { candidate entities such as prior } \\
\text { probability, relatedness between } \\
\text { the entity and its surrounding } \\
\text { context, disambiguation } \\
\text { confidence (computed in the } \\
\text { disambiguation phase), ... }\end{array}$ & $\begin{array}{l}\text { Label Vocabulary which is a kind } \\
\text { of Wikipedia-based dictionary that } \\
\text { consists of article titles, redirects } \\
\text { and link anchors; each label is } \\
\text { associated with usage statistics } \\
\text { (i.e., prior link probability) }\end{array}$ \\
\hline AIDA [7] & $\begin{array}{l}\text { Pure text processing for entity } \\
\text { spotting: a Named Entity } \\
\text { Recognition tool is used to detect } \\
\text { noun phrases as candidate entity } \\
\text { mentions; YAGO2 is used for the } \\
\text { selection of candidate entities for } \\
\text { each mention }\end{array}$ & $\begin{array}{l}\text { Combined use of popularity- } \\
\text { based prior, context-based } \\
\text { approach and graph-based } \\
\text { approach }\end{array}$ & $\mathrm{N} / \mathrm{A}$ & $\begin{array}{l}\text { YAGO2, a general purpose } \\
\text { knowledge base where each } \\
\text { entity is associated with a set of } \\
\text { labels gathered from Wikipedia } \\
\text { disambiguation pages, redirects, } \\
\text { and links }\end{array}$ \\
\hline
\end{tabular}




\begin{tabular}{|c|c|c|c|c|}
\hline $\begin{array}{c}\text { Illinois Wikifier } \\
\text { [11] }\end{array}$ & $\begin{array}{l}\text { Pure text processing for entity } \\
\text { spotting: a Named Entity } \\
\text { Recognition tool and a shallow } \\
\text { parser are used to detect named } \\
\text { entities and noun-phrases as } \\
\text { candidate entity mentions. A } \\
\text { Wikipedia-based anchor-title } \\
\text { index is used for the selection of } \\
\text { candidate entities for each } \\
\text { mention. }\end{array}$ & $\begin{array}{l}\text { Combined use of popularity- } \\
\text { based prior, context-based } \\
\text { approach and collective } \\
\text { disambiguation approach }\end{array}$ & $\mathrm{N} / \mathrm{A}$ & $\begin{array}{l}\text { Wikipedia-based anchor-title } \\
\text { index; the index, computed by } \\
\text { crawling Wikipedia, maps each } \\
\text { distinct anchor text (i.e., text with } \\
\text { embedded hyperlink) to its target } \\
\text { Wikipedia title(s). }\end{array}$ \\
\hline LUpedia [12] & $\begin{array}{l}\text { Dictionary-based: sequences of } \\
\text { tokens from the input text are } \\
\text { searched for in a custom-made } \\
\text { dictionary (Alias Dictionary) that } \\
\text { relates entities with their labels } \\
\text { and types }\end{array}$ & N/A & $\begin{array}{l}\text { Automated pruning of results: } \\
\text { pruning is based on weights that } \\
\text { reflect the following features of } \\
\text { candidate entities: the level of } \\
\text { matching between the entity's } \\
\text { alias and the input text, the } \\
\text { general "relevancy" of the } \\
\text { predicate and the class of the } \\
\text { entity (the more often they are } \\
\text { used, the more relevant they are } \\
\text { considered) }\end{array}$ & $\begin{array}{l}\text { Alias Dictionary within which each } \\
\text { alias (label) is related to: i) the } \\
\text { corresponding entity, ii) the } \\
\text { class/type of the entity, and iii) the } \\
\text { predicate defining the alias-entity } \\
\text { relationship; it is derived from } \\
\text { DBpedia and Linked Movie } \\
\text { Database (http://linkedmdb.org/) }\end{array}$ \\
\hline Denote [13] & $\begin{array}{l}\text { Multiple strategies based on text } \\
\text { processing and statistics: Inverse } \\
\text { Document Frequency for single } \\
\text { words; Named Entity Recognition } \\
\& \text { sentence chunking for multiple } \\
\text { words/phrases for deep (role- } \\
\text { based) tagging. N-grams and } \\
\text { nearest neighbor for shallow } \\
\text { tagger }\end{array}$ & $\begin{array}{l}\text { Context-based approach where } \\
\text { the best mention is selected } \\
\text { through the conditional likelihood } \\
\text { of a mention given the context's } \\
\text { subject category }\end{array}$ & $\begin{array}{l}\text { Partially automated and partially } \\
\text { user-defined pruning criteria: e.g., } \\
\text { Bayesian probability filter is } \\
\text { applied to remove non-relevant } \\
\text { candidate results, and Genetic } \\
\text { Algorithm to automate the } \\
\text { selection of "best" threshold } \\
\text { values }\end{array}$ & $\begin{array}{l}\text { A subset of DBPedia datasets. } \\
\text { Summary statistics such as } \\
\text { frequency counts are produced } \\
\text { on article categories, datatypes, } \\
\text { properties, labels, and concept } \\
\text { descriptions (abstracts). } \\
\text { Disambiguation links and } \\
\text { redirects supplement these } \\
\text { statistics for improved tagging } \\
\text { and disambiguation. Keywords } \\
\text { are linked to concepts and } \\
\text { categories. }\end{array}$ \\
\hline
\end{tabular}


The second comparison framework (Table 2) compares 'black-box' features of both commercial and 'open' tools. We refer to those features as 'black-box' since they do not reveal any information about the inner functioning of the tools, but only provide insight into their capabilities, access modes, restrictions on (free) use and the like. The selection of features was driven by the criteria that could be relevant for selecting the right tool(s) to use in a specific application case. Besides open tools, we have also included a selection of commercial tools. Tools and services for semantic tagging of text are offered by an increasing number of companies, so any attempt at providing an exhaustive list of all the available tools is destined to fail. Therefore, we have opted for a set of tools that could be considered representative based on the number of users as reported by ProgrammableWeb

(http://www.programmableweb.com/) and/or their citation within academic publications. We also opted for the tools that provide some level of free program-based access, so that interested users can test them. One should note that there is also an increasing number of enterprise metadata management solutions that offer some form of semantic tagging as one of their feature (e.g., SmartLogic.com, ContentAnalyst.com, BasisTech.com). However, as those systems do not meet one or more of our criteria, we do not review them here.

Table 2. Comparison of 'black-box' features of state-of-the-art semantic tagging tools 


\begin{tabular}{|c|c|c|c|c|c|c|c|}
\hline & URL & $\begin{array}{c}\text { Supported tagging } \\
\text { tasks }^{\star}\end{array}$ & $\begin{array}{c}\text { Knowledge } \\
\text { base(s) for entity } \\
\text { disambiguation }\end{array}$ & $\begin{array}{l}\text { Restrictions on } \\
\text { free use }\end{array}$ & $\begin{array}{c}\text { Forms of } \\
\text { program-based } \\
\text { access }\end{array}$ & $\begin{array}{l}\text { Support for } \\
\text { entity typing }\end{array}$ & $\begin{array}{l}\text { The type of } \\
\text { text the tool is } \\
\text { suitable for }\end{array}$ \\
\hline TagMe & http://tagme.di.unipi.it/ & $\begin{array}{l}\text { Document tagging (with } \\
\text { relevance score) }\end{array}$ & Wikipedia & No restrictions & RESTful API & $\begin{array}{l}\text { Wikipedia } \\
\text { categories }\end{array}$ & $\begin{array}{l}\text { Short texts like } \\
\text { tweets and } \\
\text { search snippets }\end{array}$ \\
\hline $\begin{array}{l}\text { DBpedia } \\
\text { Spotlight }\end{array}$ & $\frac{\text { http://spotlight. }}{\text { dbpedia.org/ }}$ & $\begin{array}{l}\text { Document tagging (with } \\
\text { relevance scores) }\end{array}$ & DBpedia & $\begin{array}{l}\text { No restrictions; } \\
\text { open source, } \\
\text { available under } \\
\text { Apache License } 2.0 \\
\text { (the Spotting } \\
\text { component uses } \\
\text { LingPipe with more } \\
\text { restricted license) }\end{array}$ & RESTful API & $\begin{array}{l}\text { DBpedai/ } \\
\text { Wikipedia } \\
\text { types/categories }\end{array}$ & $\begin{array}{l}\text { Longer texts like } \\
\text { Web pages or } \\
\text { Web feeds }\end{array}$ \\
\hline $\begin{array}{l}\text { Wikipedia } \\
\text { Miner }\end{array}$ & $\begin{array}{l}\frac{\mathrm{http}: / / \text { wikipedia- }}{\text { miner.cms.waikato.ac. }} \\
\underline{\underline{\mathrm{nz} /}}\end{array}$ & $\begin{array}{l}\text { Document tagging (with } \\
\text { relevance score); } \\
\text { Document topics }\end{array}$ & Wikipedia & $\begin{array}{l}\text { No restrictions; } \\
\text { open source, } \\
\text { available under GNU } \\
\text { GPLv2 license }\end{array}$ & $\begin{array}{l}\text { RESTful API; } \\
\text { Java toolkit }\end{array}$ & No direct support & $\begin{array}{l}\text { General } \\
\text { purpose; } \\
\text { equally suitable } \\
\text { for all kinds of } \\
\text { text }\end{array}$ \\
\hline AIDA & $\begin{array}{l}\text { https://github.com/yag } \\
\underline{\text { o-naga/aida }}\end{array}$ & $\begin{array}{l}\text { Document tagging (with } \\
\text { relevance scores) }\end{array}$ & YAGO2 & $\begin{array}{l}\text { No restrictions; } \\
\text { open source, } \\
\text { licensed under a } \\
\text { Creative Commons } \\
\text { Attribution- } \\
\text { NonCommercial- } \\
\text { ShareAlike } 3.0 \\
\text { Unported License }\end{array}$ & Java toolkit & YAGO types & $\begin{array}{l}\text { Bioinformatics } \\
\text { Documents and } \\
\text { Workflows }\end{array}$ \\
\hline $\begin{array}{l}\text { Illinois } \\
\text { Wikifier }\end{array}$ & $\begin{array}{l}\frac{\text { http://cogcomp.cs. }}{\text { illinois.edu/page/ }} \\
\frac{\text { software view/ }}{\text { Wikifier }}\end{array}$ & $\begin{array}{l}\text { Document tagging (with } \\
\text { relevance scores) }\end{array}$ & Wikipedia & $\begin{array}{l}\text { No restrictions; } \\
\text { open source, } \\
\text { available under } \\
\text { Illinois Open Source } \\
\text { license } \\
\text { (http://cogcomp.cs.illi } \\
\text { nois.edu/download/s } \\
\text { oftware/39) }\end{array}$ & Java toolkit & $\begin{array}{l}\text { Wikipedia } \\
\text { categories }\end{array}$ & $\begin{array}{l}\text { Short Newswire } \\
\text { Articles }\end{array}$ \\
\hline LUpedia & $\begin{array}{l}\text { http://lupedia.ontotext. } \\
\underline{\text { com/ }}\end{array}$ & $\begin{array}{l}\text { Document tagging (with } \\
\text { relevance scores) }\end{array}$ & $\begin{array}{l}\text { DBpedia, Linked } \\
\text { Movie Database }\end{array}$ & No restrictions & RESTful API & DBpedia types & $\begin{array}{l}\text { Entertainment } \\
\text { and TV related } \\
\text { texts }\end{array}$ \\
\hline Denote & $\frac{\text { http://inextweb.com/ }}{\text { denote demo }}$ & $\begin{array}{l}\text { Document tagging (with } \\
\text { relevance scores); } \\
\text { Suggestion of related } \\
\text { topics (with relevance } \\
\text { scores); } \\
\text { Role assignment }\end{array}$ & DBpedia & $\begin{array}{l}\text { Commercial; up to } \\
500 \text { API calls per } \\
\text { month are free }\end{array}$ & RESTful API & $\begin{array}{l}\text { DBpedia/ } \\
\text { Wikipedia } \\
\text { types/categories }\end{array}$ & $\begin{array}{l}\text { Long descriptive } \\
\text { documents }\end{array}$ \\
\hline
\end{tabular}




\begin{tabular}{|c|c|c|c|c|c|c|c|}
\hline $\begin{array}{l}\text { Alchemy } \\
\text { API }\end{array}$ & $\begin{array}{l}\text { http://www.alchemyapi } \\
. \mathrm{com} /\end{array}$ & $\begin{array}{l}\text { Document topics (with } \\
\text { relevance scores); } \\
\text { Document tagging (with } \\
\text { relevance scores) }\end{array}$ & $\begin{array}{l}\text { DBpedia, } \\
\text { Freebase, YAGO, } \\
\text { GeoNames, and a } \\
\text { few other } \\
\text { knowledge bases } \\
\text { from Linked Open } \\
\text { Data (LOD) Cloud } \\
\text { (http://lod- } \\
\text { cloud.net/) }\end{array}$ & $\begin{array}{l}\text { Commercial; for } \\
\text { academic use, up to } \\
30,000 \text { API calls per } \\
\text { day are free }\end{array}$ & $\begin{array}{l}\text { RESTful API; } \\
\text { toolkits for all } \\
\text { major } \\
\text { programming } \\
\text { languages } \\
\text { including Java, } \\
\text { C/C++, C\#, Ruby, } \\
\text { Python, PHP, ... }\end{array}$ & $\begin{array}{l}\text { Hundreds of } \\
\text { entity types from } \\
\text { a custom made } \\
\text { classification } \\
\text { scheme }\end{array}$ & $\begin{array}{l}\text { News articles, } \\
\text { blog posts }\end{array}$ \\
\hline $\begin{array}{l}\text { Open } \\
\text { Calais }\end{array}$ & $\begin{array}{l}\text { http://www.opencalais. } \\
\underline{\mathrm{com} /}\end{array}$ & $\begin{array}{l}\text { Document topics; } \\
\text { Document tagging (with } \\
\text { relevance scores) }\end{array}$ & $\begin{array}{l}\text { DBpedia, } \\
\text { Freebase, } \\
\text { Geonames, } \\
\text { Wikipedia, Linked } \\
\text { Movie Database }\end{array}$ & $\begin{array}{l}\text { Commercial; up to } \\
50,000 \mathrm{API} \text { calls per } \\
\text { day are free }\end{array}$ & $\begin{array}{l}\text { RESTful and } \\
\text { SOAP Web } \\
\text { service API }\end{array}$ & $\begin{array}{l}39 \text { custom- } \\
\text { defined entity } \\
\text { types; out of that, } \\
21 \text { types are } \\
\text { disambiguated to } \\
\text { LOD knowledge } \\
\text { bases }\end{array}$ & $\begin{array}{l}\text { News articles, } \\
\text { blog posts }\end{array}$ \\
\hline Wikimeta & http://wikimeta.com/ & $\begin{array}{l}\text { Document tagging (with } \\
\text { relevance scores) }\end{array}$ & DBpedia & $\begin{array}{l}\text { Commercial; up to } \\
100 \mathrm{API} \text { calls per } \\
\text { day are free; for } \\
\text { students, no } \\
\text { restrictions on use }\end{array}$ & RESTful API & $\begin{array}{l}\text { Traditional } \\
\text { Named Entity } \\
\text { types: Person, } \\
\text { Organization, } \\
\text { Product, and the } \\
\text { like }\end{array}$ & $\begin{array}{l}\text { General } \\
\text { purpose; } \\
\text { equally suitable } \\
\text { for all kinds of } \\
\text { text }\end{array}$ \\
\hline Textwise & http://textwise.com/ & $\begin{array}{l}\text { Document topics (with } \\
\text { relevance scores) }\end{array}$ & $\mathrm{N} / \mathrm{A}$ & $\begin{array}{l}\text { Commercial; } \\
\text { unspecified number } \\
\text { of API calls are free } \\
\text { ("the query limit is } \\
\text { determined by } \\
\text { TextWise at its sole } \\
\text { discretion") }\end{array}$ & RESTful API & $\begin{array}{l}\text { No support for } \\
\text { entity recognition } \\
\text { or typing; a } \\
\text { modified version } \\
\text { of the Open } \\
\text { Directory Project } \\
\text { classification } \\
\text { scheme is used } \\
\text { for doc. topics }\end{array}$ & $\begin{array}{l}\text { Equally suitable } \\
\text { for all kinds of } \\
\text { text (notable } \\
\text { application } \\
\text { content } \\
\text { authoring, } \\
\text { blogging) }\end{array}$ \\
\hline TextRazor & $\begin{array}{l}\text { http://www.textrazor. } \\
\underline{\text { com/ } /}\end{array}$ & $\begin{array}{l}\text { Document topics (with } \\
\text { relevance scores); } \\
\text { Document tagging (with } \\
\text { relevance scores) }\end{array}$ & DBpedia, Freebase & $\begin{array}{l}\text { Commercial; up to } \\
500 \mathrm{API} \text { calls per } \\
\text { day are free }\end{array}$ & $\begin{array}{l}\text { RESTful API, } \\
\text { Python client }\end{array}$ & $\begin{array}{l}\text { DBpedia and } \\
\text { Freebase types }\end{array}$ & $\begin{array}{l}\text { Legal } \\
\text { documents, } \\
\text { news articles, } \\
\text { emails }\end{array}$ \\
\hline
\end{tabular}




\section{How to choose a tool}

When deciding upon a tagging tool to use, one should primarily consider the characteristics of the task the tool is intended for [4]. In particular, the following features of the tagging task are especially important:

i) The specificity of the topics covered by the documents that are processed; for instance, tagging of domain-specific medical documents would require the use of highly specialized medical terminology, whereas general news articles could be tagged with broadly used terminology such as the one offered by DBPedia.

ii) The characteristics of the documents/text to be tagged such as length, target domain, writing style, and registers.

iii) The response time requirements of the application domain, i.e., whether the task requires realtime tagging or offline (asynchronous) tagging could be an acceptable alternative.

iv) The customizability of a tagging tool, i.e., whether the tool provides sufficient means to adapt its tunable parameters or not. This is important as tools cannot reach their best performance if they are not appropriately configured for a specific application area.

These concerns are further discussed in Table 3.

Table 3. Things to be considered when deciding upon a semantic tagger to use

\begin{tabular}{|c|c|c|}
\hline Feature & Description & State of the practice and potential issues \\
\hline $\begin{array}{l}\text { The specificity } \\
\text { of the subject } \\
\text { domain }\end{array}$ & $\begin{array}{l}\text { The content can be domain specific } \\
\text { (i.e., focused on one particular } \\
\text { domain such as medicine or law), or } \\
\text { more broad and general (i.e., } \\
\text { covering a wide range of topics of } \\
\text { general interest). }\end{array}$ & $\begin{array}{l}\text { Due to their reliance on general knowledge bases (e.g., } \\
\text { Wikipedia, DBpedia, and Freebase), a large majority of the } \\
\text { taggers discussed in this paper are better suited for general } \\
\text { content. }\end{array}$ \\
\hline $\begin{array}{l}\text { The } \\
\text { characteristics } \\
\text { of the text to be } \\
\text { tagged }\end{array}$ & $\begin{array}{l}\text { The length of the text, the style of } \\
\text { writing and the use of jargon (e.g., } \\
\text { scientific papers vs. news articles vs. } \\
\text { tweets/status updates) }\end{array}$ & $\begin{array}{l}\text { The majority of existing taggers do not specify the type of text } \\
\text { they are intended for and claim that if appropriately configured, } \\
\text { they are able to cover different forms of textual content. Still, } \\
\text { some tools are specifically targeted at a certain category of } \\
\text { text. For instance, TagMe is particularly suitable for short texts } \\
\text { such as tweets, status updates and search result snippets, } \\
\text { whereas OpenCalais is developed with primary orientation on } \\
\text { news articles. }\end{array}$ \\
\hline $\begin{array}{l}\text { The response } \\
\text { time } \\
\text { requirements of } \\
\text { the application } \\
\text { domain } \\
\text { (asynchronous } \\
\text { vs. } \\
\text { synchronous } \\
\text { response) }\end{array}$ & $\begin{array}{l}\text { This aspect of the tagging task is } \\
\text { related to the efficiency issues that } \\
\text { stem from the use of large-scale } \\
\text { knowledge bases in the tagging } \\
\text { process. By affecting the speed of } \\
\text { the tagger, it (indirectly) affects } \\
\text { users' satisfaction with the tool, and } \\
\text { eventually their acceptance and } \\
\text { adoption of the tool. }\end{array}$ & $\begin{array}{l}\text { The processing speed may not be a factor if real-time results } \\
\text { are not required; for instance, if the task is to develop a web } \\
\text { crawler that would index and semantically tag visited Web } \\
\text { pages. However, if a usage scenario requires real-time results, } \\
\text { one should look for semantic taggers that are efficient even in } \\
\text { real-time. One strategy, applied in TagMe, is to make a 'trade- } \\
\text { off' between performance and speed, and achieve higher } \\
\text { speed by 'sacrificing' slight performance gains that could stem } \\
\text { from applying more sophisticated but computationally more } \\
\text { intensive techniques. }\end{array}$ \\
\hline $\begin{array}{l}\text { The } \\
\text { customizability }\end{array}$ & $\begin{array}{l}\text { The default configuration of a tagger } \\
\text { is often only suitable for some }\end{array}$ & $\begin{array}{l}\text { The main challenge here lies in allowing users to tune the } \\
\text { tagger with respect to the key issues, such as specificity and }\end{array}$ \\
\hline
\end{tabular}




\begin{tabular}{|l|l|l|}
\hline $\begin{array}{l}\text { of the tagging } \\
\text { tool }\end{array}$ & $\begin{array}{l}\text { undemanding tagging tasks. } \\
\text { Accordingly, a tagging tool tends to } \\
\text { be more usable if it allows its users } \\
\text { to define a custom configuration } \\
\text { matching the specificities of the task } \\
\text { at hand. }\end{array}$ & $\begin{array}{l}\text { comprehensiveness, without being concerned with the details } \\
\text { of the tool's parameters and internal functioning. } \\
\text { Many of today's tagging tools tend to mitigate this challenge by } \\
\text { grouping related parameters and exposing only a couple of } \\
\text { generalized and intuitively-named parameter (e.g., } \\
\text { confidence). This way the tools make a trade-off between } \\
\text { advantages obtainable from highly customized tagging engine } \\
\text { and erroneous results that might follow from inappropriately set } \\
\text { parameter values. }\end{array}$ \\
\hline
\end{tabular}

\section{Concluding Remarks}

Automated semantic tagging technology facilitates deeper analysis of the significant amount of text that is generated worldwide either in the form of user generated content such as tweets and weblogs, or enterprise specific content such as corporate documents and reports. This technology could allow for more accurate and semantics-aware organization, search and retrieval of textual information. However, we also need to highlight the importance of choosing the most suitable semantic tagger (one or a combination of them) for a target application domain by considering factors such as those outlined in Table 3. The deployment of suitable automated semantic tagging technology can significantly enhance textual processing by moving beyond syntactical information and into the realm of deeper textual semantics.

\section{References}

1. S. Feldman. The Answer Machine (Synthesis Lectures on Information Concepts, Retrieval, and Services). Morgan \& Claypool Publishers, 2012.

2. G. S. Ingersoll, T. S. Morton, and A. L. Farris. Taming Text - How to Find, Organize, and Manipulate It. Manning Publications Co., 2013.

3. V. Uren, P. Cimiano, J. Iria, S. Handschuh, M. Vargas-Vera, E. Motta, S. Ciravegna, "Semantic annotation for knowledge management: Requirements and a survey of the state of the art," Journal of Web Semantics, vol. 4, no.1, 2005, pp. 14-28.

4. D. Maynard, "Benchmarking Textual Annotation Tools for the Semantic Web," Proceedings of 6th International Conference on Language Resources and Evaluation, Marrakech, Morocco, 2008. URL: http://gate.ac.uk/sale//rec2008/benchmarking.pdf

5. M. Cornolti, P. Ferragina, M. Ciaramita, "A Framework for Benchmarking Entity-Annotation Systems," Proceedings of the 22nd International World Wide Web Conference, Rio de Janeiro, Brazil, 2013, pp. 249260.

6. D. Milne and I. H. Witten, "An open-source toolkit for mining Wikipedia," Journal of Artificial Intelligence, vol.194 (January 2013), 2013, pp. 222-239.

7. J. Hoffart, M. A. Yosef, I. Bordino, H. Fürstenau, M. Pinkal, M. Spaniol, B. Taneva, S. Thater, and G. Weikum, "Robust disambiguation of named entities in text," Proceedings of the Conference on Empirical Methods in Natural Language Processing, Edinburgh, UK, 2011, pp. 782-792.

8. D. Milne and I. H. Witten, "Learning to link with Wikipedia," Proceedings of the 17th ACM Conference on Information and knowledge management, Napa Valley, California, USA, 2008, pp. 509-518.

9. R. Feldman and J. Sanger. The Text Mining Handbook: Advanced Approaches in Analyzing Unstructured Data. Cambridge University Press, 2006.

10. P. N. Mendes, M. Jakob, A. García-Silva, C. Bizer, "DBpedia spotlight: shedding light on the web of documents," Proceedings of the 7th International Conference on Semantic Systems, New York, USA, 2011, pp. 1-8. 
11. L. Ratinov, D. Roth, D. Downey, M. Anderson, "Local and global algorithms for disambiguation to Wikipedia," Proceedings of the 49th Annual Meeting of the Association for Computational Linguistics: Human Language Technologies, Portland, Oregon, USA, 2011, pp.1375-1384.

12. P. Mihaylov, D4.5 Integration of Advanced Modules in the Annotation Framework. Deliverable of the NoTube FP7 EU project (project no. 231761), 2011. Available at:

http://notube3.files.wordpress.com/2012/01/notube d4-5-integration-of-advanced-modules-in-annotationframework-vm33.pdf

13. J. Cuzzola, Z. Jeremic, E. Bagheri, D. Gasevic, J. Jovanovic, R. Bashash, "Semantic Tagging with Linked Open Data," Proceedings of the $4^{\text {th }}$ Canadian Semantic Web Symposium, Montreal, Canada, 2013. URL: http://ceur-ws.org/Vol-1054/paper-13.pdf

\section{Authors' bios}

Jelena Jovanovic is an Associate Professor at Univeristy of Belgrade. Her broad research interests include semantic technologies and technology enhanced learning. She can be reached at http://jelenajovanovic.net.

Ebrahim Bagheri is an Assistant Professor at Ryerson University where he leads the Laboratory for Systems, Software and Semantics $\left(\mathrm{LS}^{3}\right)$. His broad research interests are large-scale software reuse and semantic Web technologies.

John Cuzzola s a Research Associate at Ryerson University. His research interests are in the areas of artificial intelligence, natural language processing, and machine learning.

Dragan Gasevic is an Associate Professor and Canada Research Chair in Semantic and Learning Technologies at Athabasca University. His research interests are at the intersect of computational, socio-cognitive, and design aspects of information seeking, sensemaking, and learning. He can be reached at http://dgasevic.athabascau.ca.

Zoran Jeremic is a Post-Doctoral Fellow at Ryerson University. His broad research interests is in the domain of technology enhanced learning. He can be reached at http://zoranjeremic.org.

Reza Bashash is a serial entrepreneur and CTO \& Founder of Denote Enterprises Inc. His area of interests are artificial intelligence and search technologies. Reza can be reached at bashash[at]gmail[dot]com. 